策 



\section{Theoretische Mechanik}

von

Herbert R. Petry und Bernard Christiaan Metsch

Oldenbourg Verlag München Wien 


\section{Zu den Autoren:}

PD Dr. Bernard Christiaan Metsch und Prof. Dr. Herbert R. Petry forschen und lehren am Helmholtz-Institut für Strahlen- und Kernphysik der Universität Bonn.

Bibliografische Information Der Deutschen Bibliothek

Die Deutsche Bibliothek verzeichnet diese Publikation in der Deutschen Nationalbibliografie; detaillierte bibliografische Daten sind im Internet über $<$ http://dnb.ddb.de $>$ abrufbar.

(C) 2005 Oldenbourg Wissenschaftsverlag $\mathrm{GmbH}$

Rosenheimer Straße 145, D-81671 München

Telefon: (089) 45051-0

www.oldenbourg.de

Das Werk einschließlich aller Abbildungen ist urheberrechtlich geschützt. Jede Verwertung außerhalb der Grenzen des Urheberrechtsgesetzes ist ohne Zustimmung des Verlages unzulässig und strafbar. Das gilt insbesondere für Vervielfältigungen, Übersetzungen, Mikroverfilmungen und die Einspeicherung und Bearbeitung in elektronischen Systemen.

Lektorat: Kathrin Mönch

Herstellung: Anna Grosser

Umschlagkonzeption: Kraxenberger Kommunikationshaus, München

Gedruckt auf säure- und chlorfreiem Papier

Druck: Grafik + Druck, München

Bindung: R. Oldenbourg Graphische Betriebe Binderei GmbH

ISBN 3-486-24673-9 